\begin{tabular}{|c|c|c|c|c|c|c|}
\hline \multirow{4}{*}{ Impact Factor: } & ISRA (India) & $=3.117$ & SIS (USA) & $=0.912$ & ICV (Poland) & $=6.630$ \\
\hline & ISI (Dubai, UAE & $=0.829$ & РИНЦ (Russia & $=0.156$ & PIF (India) & $=1.940$ \\
\hline & GIF (Australia) & $=0.564$ & ESJI (KZ) & $=8.716$ & IBI (India) & $=4.260$ \\
\hline & JIF & $=1.500$ & SJIF (Morocco & $=\mathbf{5 . 6 6 7}$ & OAJI (USA) & $=0.350$ \\
\hline
\end{tabular}

\section{SOI: 1.1/TAS DOI: 10.15863/TAS International Scientific Journal Theoretical \& Applied Science}

\author{
p-ISSN: 2308-4944 (print) e-ISSN: 2409-0085 (online) \\ Year: 2019 Issue: $03 \quad$ Volume: 71
}

Published: $23.03 .2019 \quad \underline{\text { http://T-Science.org }}$
QR - Issue
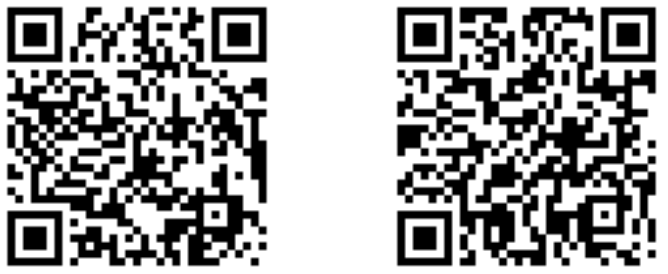

Yusir Fuad Mammadov

Associate professor, Departments of Therapeutic dentistry, Azerbaijan Medical University, Baku

yuska50@rambler.ru

Djavid Algish Safarov

Researchers, Departments of Therapeutic dentistry, Azerbaijan Medical University, Baku safarovjavid303@gmail.com

Ahmad Vaqif Orujov Assistant professor Departments of Therapeutic dentistry, Azerbaijan Medical University, Baku

ehmed.orucov@list.ru

Elmira Ramiz Alieva

Assistant professor Departments of Prosthetic dentistry, Azerbaijan Medical University, Baku elya.stomatoloq@mail.ru

\title{
THE IMPORTANCE OF SMOKING IN THE GENESIS OF DISEASES OF THE ORGANS AND TISSUES OF THE ORAL CAVITY
}

\begin{abstract}
In the article are presents materials on the assessment of the dental status of students-smokers of tobacco in the process of treatment and preventive measures. A survey and survey of 380 students of the Azerbaijan Medical University in Baku were conducted and three clinical groups were formed: Group 1 - removal of plaque using a Vector piezoelectric ultrasound machine; Group 2 - the use of air-abrasive apparatus Air Flo C2; Group 3 the use of hand tools - Gracie Curet standard stiffness. A relatively high level of incidence of caries and periodontal diseases was observed in the group of smoking students. In the more remote periods of clinical studies, recurrence of inflammation in periodontal tissues was observed most often in the second group, where the ER-Flo C2 system was used.

Key words: smoking, students, caries, periodontitis, treatments.

Language: Russian

Citation: Mammadov, Y. F., Safarov, D. A., Orujov, A. V., \& Alieva, E. R. (2019). The importance of smoking in the genesis of diseases of the organs and tissues of the oral cavity. ISJ Theoretical \& Applied Science, 03 (71), 379-384.
Soi: http://s-o-i.org/1.1/TAS-03-71-29
Doi: crossef https://dx.doi.org/10.15863/TAS.2019.03.71.29

\section{О ЗНАЧЕНИИ КУРЕНИЯ В ГЕНЕЗЕ ЗАБОЛЕВАНИЙ ОРГАНОВ И ТКАНЕЙ ПОЛОСТИ РТА}

Аннотация: В статье представлены материаль по оценке стоматологического статуса студентовкурильщиков табака в прочессе лечебно-профилактических мероприятий. Было проведено обследование и опрос 380 студентов Азербайджанского Медицинского Университета в г. Баку и сформированы три клинические группь: 1 группа - удаление налета с использованием пьезоэлектрического ультразвукового aпnарата Vector; 2 группа - использование воздушно-абразивного аппарата Эр-Фло С2; 3 группа использование ручных инструментов - кюрет Грейси стандартной жесткости. В группе курящих студентов наблюдался сравнительно высокий уровень частоты встречаемости кариеса и заболеваний пародонта. В более отдаленные сроки клинических исследований рециидивы воспаления в тканях пародонта наблюдались чаще всего во второй группе, где применялась система ЭР-Фло С2.
\end{abstract}




\begin{tabular}{|c|c|c|c|c|c|c|}
\hline \multirow{4}{*}{ Impact Factor: } & ISRA (India) & $=3.117$ & SIS (USA) & $=0.912$ & ICV (Poland) & $=6.630$ \\
\hline & ISI (Dubai, UAE & $=0.829$ & РИНЦ (Russia & $=0.156$ & PIF (India) & $=1.940$ \\
\hline & GIF (Australia) & $=0.564$ & ESJI (KZ) & $=8.716$ & IBI (India) & $=4.260$ \\
\hline & JIF & $=1.500$ & SJIF (Morocco & $=5.667$ & OAJI (USA) & $=0.350$ \\
\hline
\end{tabular}

Ключевые слова: курение, студенты, кариес, пародонтит, лечение

\section{İntroduction}

По итогам детального анализа результатов научных исследований все еще актуальной для практической медицины и стоматологии в настоящее время представляется проблема высокого уровня распространенности и интенсивности стоматологических заболеваний [1, с.67-75; 2, с.67-72; 3, с.10-17]. Основными этиологическими факторами заболеваний органов и тканей рта являются: патогенные и условнопатогенные микроорганизмы зубной бляшки и продукты их обмена; определенные «благоприятные» условия в полости рта, способные усиливать патогенетическую активность бактерий и продлевать сроки их действия; общие экзо- и эндогенные факторы, определяющие сопротивляемость тканей к патогенным воздействиям $[4$, с.3-9; 5 , с.11-17; 6 , c.1008-1013]. Заболевания пищеварительной, эндокринной систем, гематологические заболевания, прием сильнодействующих лекарственных препаратов и некоторые изменения по гормональному статусу в период беременности и полового созревания приводят к снижению иммунологической реактивности на местном и общем уровнях [7, с.116-118; 8, с.8996]. На этом фоне происходит ослабление защитно-приспособительных механизмов, что обусловлено такими структурными и функциональными факторами, как высокая степень регенерации эпителиальной ткани, состояние микроциркуляторного роста, лимфоцитарный барьер, скорость выделения, вязкость и буферная емкость слюны, содержание в полости рта иммуноглобулинов и лизоцима [9, c.170-173; 10, с.152-163]. Выраженное влияние на состояние полости рта оказывают так называемые факторы риска, связанные с социальноэкономическими условиями проживания и профессиональной деятельности, а также поведенческими особенностями и привычками людей [11, с.112-129; 12, с.728-735; 13, с.61-76]. Опасную группу представляют собой некоторые вредные привычки - курение, употребление алкоголя и наркотических средств. Табакокурение в структуре Международной классификации болезней (МКБ-10) отнесена к категории «Умственные и поведенческие расстройства, обусловленные использованием психоактивных соединений» и является серьезной и все еще нерешённой проблемой современной медицины. По данным Всемирной Организации Здравоохранения - - ВО3, (2009), распространённость табакокурения среди различных возрастно-половых групп взрослого населения составила в среднем 35-40\%, при этом, среди мужчин - 55-61\%, а среди представителей женского пола - 20-22\% и занимает первое место в мире среди основных причин смертности [14, с.23-26; 15, с.966-976; 16, с.122]. Необходимо отметить, что под действием табачной интоксикации у женщин развивается структурное истощение в жизненно-важных системах организма, что впоследствии становится причиной расстройства половой функции, нарушений репродуктивной способности, бесплодия $\quad[17, \quad$ c.25-28; 18, c.643-647]. Исследуемая вредная привычка очень часто выявляется среди молодёжи, ведет к ухудшению здоровья и сокращению продолжительности их жизни [19, с.20-28].

Таким образом, табакокурение на фоне образования твёрдого пигментированного налета, изменения состава слюны и десневой жидкости, поражения слизистой оболочки, наличия факторов риска возникновения различных новообразований, является одним из важных факторов риска возникновения и развития воспалительных и деструктивных заболеваний рта вне зависимости от возрастных показателей [20, с.952-957].

\section{Materials and Methods}

На первом этапе исследований с 2015 по 2018 гг были обследованы 180 курящих и 200 некурящих студента в Медицинском Университете г. Баку в возрасте 18 - 22 года. Курящими, согласно рекомендации Всемирной Организации Здравоохранения (ВО3), признавались лица, которые в течении длительного времени выкуривали минимум от 5 до 10 сигарет в день. Индекс курения рассчитывался по формуле: Индекс курения = (число сигарет, выкуриваемых в день) $\times 12$. Степень никотиновой зависимости определялась опросником, разработанным Карлом Фагерстромом (Fagerström Test for Nicotine Dependence - FTND) (Fagerstrom К.О., 1989) [21, с.164-189; 22, с.159-182]. В карте обследования стоматологического больного заносились данные результаты исследования, индексной оценки изменений в твердых тканях зубов (КПУ). Клиническое обследование до и после лечения, а также через 10 дней, 1, 2 и 6 месяцев включало определение клинических гигиенических и пародонтальных индексов - Силнесс - Лоэ (Silness, Löe, 1962), Индекс Мюллемана (Mühlemann, 1971) в модификации Коуэлл (Cowell I., 1975). Для достижения поставленной цели были сформированы три клинические группы: 1 группа - удаление налета с использованием пьезоэлектрического ультразвукового аппарата Vector; 2 группа - удаление налета с использованием воздушно-абразивного аппарата Эр-Фло С2; 3 группа - удаление налета с использованием ручных инструментов - кюрет Грейси стандартной жесткости. Статистическую 


\begin{tabular}{|c|c|c|c|c|c|c|}
\hline \multirow{4}{*}{ Impact Factor: } & ISRA (India) & $=3.117$ & SIS (USA) & $=0.912$ & ICV (Poland) & $=6.630$ \\
\hline & ISI (Dubai, UAE & $=0.829$ & РИНЦ (Russia & $=0.156$ & PIF (India) & $=1.940$ \\
\hline & GIF (Australia) & $=0.564$ & ESJI (KZ) & $=8.716$ & IBI (India) & $=4.260$ \\
\hline & JIF & $=1.500$ & SJIF (Morocco & $=5.667$ & OAJI (USA) & $=0.350$ \\
\hline
\end{tabular}

обработку полученных результатов проводили с использованием методов вариационной статистики. Для оценки межгрупповых различий значений признаков применяли $\mathrm{t}$-критерий Стьюдента и непараметрический U-критерий Уилкоксона-МаннаУитни. Статистическое различие между группами считалось достоверным при значении $\mathrm{p}<0,05$. Статистическая обработка материала выполнялась с использованием стандартного пакета программ прикладного статистического анализа (Microsoft Excel, Statistica for Windows v. 7.0).

\section{Results and Discussion}

Необходимо отметить, что менее 25\% опрошенных студентов, многие из которых начали курить еще до поступления в университет, причиной курения среди исследуемых мотивирующих факторов называли пример окружающих или же желание подражать им, а также «от нечего делать». Среди них имели желание и старались избавиться от курения 55,5\% и у них был обнаружен меньший индекс курения, что свидетельствовало о слабой интенсивности курения или меньшем количестве выкуриваемых в день сигарет (табл. 1).

Таблица 1. Оценка статуса курения и степени никотиновой зависимости у студентов.

\begin{tabular}{|l|c|c|}
\hline \multicolumn{1}{|c|}{ Признак } & $\begin{array}{c}\text { Желающие бросить курить } \\
(\mathrm{n}=100)\end{array}$ & $\begin{array}{c}\text { Отвергающие возможность } \\
\text { бросить курить }(\mathrm{n}=80)\end{array}$ \\
\hline $\begin{array}{l}\text { Степень никотиновой } \\
\text { зависимости (тест } \\
\text { Фагерстрема), баллы }\end{array}$ & $3,76 \pm 0,17 *$ & $5,35 \pm 0,18$ \\
\hline $\begin{array}{l}\text { Мотивация к отказу от } \\
\text { курения, баллы }\end{array}$ & $7,05 \pm 0,07 *$ & $3,73 \pm 0,05$ \\
\hline ИКЧ, пачка-лет & $2,35 \pm 0,12 *$ & $5,17 \pm 0,18$ \\
\hline
\end{tabular}

Примечание: * - статистически значимое отличие показателей желающих бросить курить пациентов от соответствуюших показателей отвергающчих возможность бросить курить $(p<0,001)$

Результаты сравнительной индексной оценки обследуемых лиц, как желающих бросить курить, так и отвергающих такое течение обстоятельств, регистрировал максимальные значения по всем изучаемым факторам во второй группе, за исключением показателей, характеризующих степень мотивации студентов к отказу от табакокурения 7,05 $\pm 0,07$ и 3,73 $\pm 0,05$ баллов, в первой и во второй группах, соответственно $(\mathrm{p}<0,001)$. Среди этих студентов был выявлен высокий уровень распространенности и интенсивности кариеса зубов по всем составляющим индекса КПУ. Так, частота встречаемости кариозного процесса у них составила $4,37 \pm 0,12$ и 4,86 $\pm 0,15$ балла, что было значительно выше, чем в контрольной группе $(\mathrm{p}<0,05)$ (табл.2).

Таблица 2. Состояние полости рта у обследуемых студентов.

\begin{tabular}{|l|c|c|c|}
\hline $\begin{array}{c}\text { Показатели состояния } \\
\text { полости рта }\end{array}$ & $\begin{array}{c}\text { Курс } \\
\text { обучения }\end{array}$ & $\begin{array}{c}\text { Курящие } \\
(\mathrm{n}=180)\end{array}$ & $\begin{array}{c}\text { Некурящие } \\
(\mathrm{n}=200)\end{array}$ \\
\hline \multirow{2}{*}{ Интенсивность кариеса } & $3 \mathrm{\kappa ypc}$ & $4,37 \pm 0,12$ & $3,98 \pm 0,09 *$ \\
\cline { 2 - 4 } & $5 \mathrm{\kappa ypc}$ & $4,86 \pm 0,15$ & $4,42 \pm 0,11 *$ \\
\hline \multirow{2}{*}{ К } & 3 курс & $1,89 \pm 0,07$ & $1,18 \pm 0,05 *$ \\
\hline \multirow{2}{*}{$\Pi$} & 5 курс & $2,04 \pm 0,07$ & $1,15 \pm 0,05 *$ \\
\hline \multirow{2}{*}{$\mathrm{y}$} & $3 \mathrm{\kappa ypc}$ & $2,11 \pm 0,08$ & $2,51 \pm 0,08 *$ \\
\cline { 2 - 4 } & 5 курс & $2,42 \pm 0,09$ & $2,98 \pm 0,10 *$ \\
\hline
\end{tabular}

Примечание: *-достоверность различий при р<0,05 по сравнению с курящими студентами 


\begin{tabular}{|c|c|c|c|c|c|c|}
\hline \multirow{4}{*}{ Impact Factor: } & ISRA (India) & $=3.117$ & SIS (USA) & $=0.912$ & ICV (Poland) & $=6.630$ \\
\hline & ISI (Dubai, UAE & $=0.829$ & РИНЦ (Russia) & $=0.156$ & PIF (India) & $=1.940$ \\
\hline & GIF (Australia) & $=0.564$ & ESJI (KZ) & $=8.716$ & IBI (India) & $=4.260$ \\
\hline & JIF & $=1.500$ & SJIF (Morocco) & $=5.667$ & OAJI (USA) & $=0.350$ \\
\hline
\end{tabular}

При исследовании компонентов индекса КПУ выраженная разница в показателях была обнаружена и по частоте встречаемости удаленных зубов. При сравнительной оценке полученных данных у курящих студентов чаще, чем у их оппонентов в контрольной группе диагностировались мягкие и твердые зубные отложения, а также патологические пародонтальные карманы (табл. 3).

Таблица 3. Состояние полости рта у студентов (абс. ч.; \%).

\begin{tabular}{|c|c|c|c|c|c|}
\hline $\begin{array}{c}\text { Показатели состояния } \\
\text { полости рта } \\
\end{array}$ & $\begin{array}{c}\text { Курс } \\
\text { обучения }\end{array}$ & \multicolumn{2}{|c|}{$\begin{array}{c}\text { Курящие } \\
(\mathrm{n}=180)\end{array}$} & \multicolumn{2}{|c|}{$\begin{array}{l}\text { Некурящие } \\
(\mathrm{n}=200)\end{array}$} \\
\hline \multirow{2}{*}{ Индекс Гигиены } & 3 курс & \multicolumn{2}{|c|}{$1,48 \pm 0,014$} & \multicolumn{2}{|c|}{$1,22 \pm 0,011 *$} \\
\hline & 5 курс & \multicolumn{2}{|c|}{$1,50 \pm 0,015$} & \multicolumn{2}{|c|}{$1,25 \pm 0,013 *$} \\
\hline \multirow{2}{*}{$\begin{array}{l}\text { Клинически здоровый } \\
\text { Пародонт }\end{array}$} & 3 курс & 5 & $2,78 \pm 1,22$ & 18 & $9,0 \pm 2,02 *$ \\
\hline & 5 курс & - & - & 7 & $3,5 \pm 1,30 *$ \\
\hline \multirow{2}{*}{$\begin{array}{l}\text { Наличие кровоточивости } \\
\text { десен }\end{array}$} & 3 курс & 64 & $35,6 \pm 3,57$ & 93 & $46,5 \pm 3,53$ * \\
\hline & 5 курс & 6 & $3,3 \pm 1,34$ & 33 & $16,5 \pm 2,62 *$ \\
\hline \multirow[b]{2}{*}{ Наличие зубного камня } & 3 курс & 83 & $46,1 \pm 3,72$ & 73 & $36,5 \pm 3,40$ \\
\hline & 5 курс & 130 & $72,2 \pm 3,34$ & 129 & $64,5 \pm 3,38$ \\
\hline \multirow{2}{*}{$\begin{array}{l}\text { Наличие десневых } \\
\text { Карманов }\end{array}$} & 3 курс & 28 & $15,6 \pm 2,70$ & 16 & $8,0 \pm 1,92 *$ \\
\hline & 5 курс & 44 & $24,4 \pm 3,20$ & 31 & $15,5 \pm 2,56 *$ \\
\hline
\end{tabular}

Уровень гигиены полости рта курящих студентов можно оценен как плохой. Значения гигиенического индекса в контрольной группе были достоверно ниже по сравнению со курящими студентами. В ходе лечебно-профилактических мероприятий после профессиональной гигиены полости рта и удаления зубных отложений повторное клиническое обследование проводили через 15 дней, 1, 2, 6 месяцев (табл.4).

Таблица 4. Динамика изменения значений индекса Мюллемана в группах.

\begin{tabular}{|l|c|c|c|c|c|}
\hline \multirow{2}{*}{ Методы } & \multicolumn{5}{|c|}{ Сроки наблюдения } \\
\cline { 2 - 6 } & До лечения & 15 дней & 1 месяц & 2 месяца & 6 месяцев \\
\hline Vector (15) & $2,56 \pm 0,042$ & $0,21 \pm 0,020^{*}$ & $0,24 \pm 0,028^{*}$ & $0,72 \pm 0,035^{*}$ & $0,83 \pm 0,040^{*}$ \\
\hline ЭР-Фло С2 (20) & $2,52 \pm 0,050$ & $0,22 \pm 0,024^{*}$ & $0,18 \pm 0,027^{*}$ & $0,86 \pm 0,035^{*}$ & $0,98 \pm 0,042^{*}$ \\
\hline $\mathrm{P}_{1}$ & $>0,05$ & $>0,05$ & $>0,05$ & $<0,01$ & $<0,05$ \\
\hline Кюреты Грейси (17) & $2,52 \pm 0,065$ & $0,13 \pm 0,018^{*}$ & $0,17 \pm 0,025^{*}$ & $0,61 \pm 0,032^{*}$ & $0,69 \pm 0,043^{*}$ \\
\hline $\mathrm{P}_{1}$ & $>0,05$ & $<0,01$ & $<0,05$ & $<0,05$ & $<0,01$ \\
\hline $\mathrm{P}_{2}$ & $>0,05$ & $<0,01$ & $>0,05$ & $<0,001$ & $<0,001$ \\
\hline
\end{tabular}

Примечание: *-статистически достоверное различие относительно до лечения ( $p<0,001)$;

$P_{1}-$ достоверность различия относительно первого метода;

$\mathrm{P}_{2}$ - достоверность различия относительно второго метода.

При первичном осмотре у всех пациентов определялась неудовлетворительная гигиена полости рта и кровоточивость десны, степень которой по индексу Мюллемана составляла в среднем 2,6 $\pm 0,3 \quad(\mathrm{p}<0,001)$. Через месяц после терапии значения исследуемых индексов свидетельствовали о значительном улучшении гигиенического состояния ротовой полости (табл.5). 


\begin{tabular}{|c|c|c|c|c|c|c|}
\hline \multirow{4}{*}{ Impact Factor: } & ISRA (India) & $=3.117$ & SIS (USA) & $=0.912$ & ICV (Poland) & $=6.630$ \\
\hline & ISI (Dubai, UAE & $=0.829$ & РИНЦ (Russia & $=0.156$ & PIF (India) & $=1.940$ \\
\hline & GIF (Australia) & $=0.564$ & ESJI (KZ) & $=8.716$ & IBI (India) & $=4.260$ \\
\hline & JIF & $=1.500$ & SJIF (Morocco & $=5.667$ & OAJI (USA) & $=0.350$ \\
\hline
\end{tabular}

Таблица 5. Показатели индекса Силнесс-Лоэ в группах.

\begin{tabular}{|l|c|c|c|c|c|}
\hline \multirow{2}{*}{ Методы } & \multicolumn{5}{|c|}{ Сроки наблюдения } \\
\cline { 2 - 6 } & До лечения & 15 дней & 1 месяц & 2 месяца & 6 месяцев \\
\hline Vector & $2,61 \pm 0,058$ & $0,18 \pm 0,020^{*}$ & $0,20 \pm 0,014^{*}$ & $0,79 \pm 0,013^{*}$ & $0,84 \pm 0,010^{*}$ \\
\hline ЭР-Фло C2 & $2,56 \pm 0,050$ & $0,17 \pm 0,016^{*}$ & $0,25 \pm 0,008^{*}$ & $0,97 \pm 0,015^{*}$ & $1,09 \pm 0,018^{*}$ \\
\hline $\mathrm{P}_{1}$ & $>0,05$ & $>0,05$ & $<0,05$ & $<0,01$ & $<0,001$ \\
\hline $\begin{array}{l}\text { Кюреты } \\
\text { Грейси }\end{array}$ & $2,65 \pm 0,055$ & $0,12 \pm 0,010^{*}$ & $0,15 \pm 0,016^{*}$ & $0,67 \pm 0,021^{*}$ & $0,77 \pm 0,026^{*}$ \\
\hline $\mathrm{P}_{1}$ & $>0,05$ & $<0,05$ & $<0,05$ & $<0,01$ & $<0,05$ \\
\hline $\mathrm{P}_{2}$ & $>0,05$ & $<0,05$ & $<0,01$ & $<0,001$ & $<0,001$ \\
\hline
\end{tabular}

Примечание: * - статистически достоверное различие относительно до лечения ( $p<0,001)$;

$P_{1}$ - достоверность различия относительно первого метода;

$\mathrm{P}_{2}$ - достоверность различия относительно второго метода.

Показатели индекса, характеризующего «экологическую» ситуацию полости рта обследуемых студентов, индекса Силнесс - Лоэ значительно снизились уже на начальном после лечения этапе клинических наблюдений в третьей

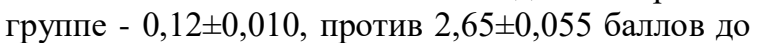
начала терапевтического курса $(\mathrm{p}<0,05)$. В более отдаленные сроки клинических исследований после проведения лечебно-профилактических мер рецидивы воспалительного процесса в тканях пародонта наблюдались чаще всего во второй группе, где применялась система ЭР-Фло С2, что, по нашему мнению, может быть связано с выраженной шероховатостью поверхности обрабатываемых зубов.

Таким образом, выявленные в ходе клинических исследований и индексной оценки состояния гигиены полости рта и тканей пародонта результаты свидетельствовали о прямой зависимости состояния обработанной поверхности зубов, а также мягких околозубных тканей от наличия вредной привычки и используемых лечебно-профилактических методов.

\section{References:}

1. Yermukhanova, G. T., et al. (2017). Predvaritelnaya otsenka stomatologicheskogo zdorov'ya detey shkol'nogo vozrasta g. Almaty s primeneniyem yevropeyskikh indikatorov (EGOHID). Pediatriya $i$ detskaya khirurgiya, №1 (87), 67-75.

2. Khamadeyeva, A. M., Nogina, N. V., Luchsheva, L. F., \& Baymuratova, L. R. (2018). Osobennosti stomatologicheskogo zdorov'ya detey $\mathrm{v}$ regione $\mathrm{s}$ neblagopriyatnoy ekologicheskoy situatsiyey na primere g. Chapayevska Samarskoy oblasti. Dalnevostochnyy meditsinskiy zhurnal, N 1, 6772.

3. Abid, A., et al. (2015). Prevalence and Severity of Oral Diseases in the Africa and Middle East Region. Advances in Dental Research, Vol. 27(1), 10-17.
4. Melekhov. S. V., Kolesnikova, N. V., \& Ovcharenko, Y. S. (2013). Sostoyaniye mestnogo immuniteta i mikrobiotsenoza polosti rta u bol'nykh khronicheskim generalizovannym parodontitom. Parodontologiya, 18(1), 3-9.

5. Igor, J., et al. (2018). Increased Detection Rate of Prevotella Intermedia among Pregnant Periodontitis Patients in Romania. Biomed J Sci \& Tech Res, 2(1), 11-17.

6. Lopez-Oliva, I., et al. (2018). Dysbiotic Subgingival Microbial Communities in Periodontally Healthy Patients With Rheumatoid Arthritis. Arthritis Rheumatol, 70(7), 1008-1013.

7. Gazhva, S. I., \& Igolkina, N. A. (2013). Vzaimosvyaz' zabolevaniy vnutrennikh organov i sostoyaniya polosti rta. Terapevticheskiy arkhiv, 85,10, 116-118. 


\begin{tabular}{|c|c|c|c|c|c|c|}
\hline \multirow{4}{*}{ Impact Factor: } & ISRA (India) & $=3.117$ & SIS (USA) & $=0.912$ & ICV (Poland) & $=6.630$ \\
\hline & ISI (Dubai, UAE & $=0.829$ & РИНЦ (Russia) & $=0.156$ & PIF (India) & $=1.940$ \\
\hline & GIF (Australia) & $=0.564$ & ESJI (KZ) & $=8.716$ & IBI (India) & $=4.260$ \\
\hline & JIF & $=1.500$ & SJIF (Morocco) & $=5.667$ & OAJI (USA) & $=0.350$ \\
\hline
\end{tabular}

8. Solomon, S. M., et al. (2017). Risk predictors in periodontal disease. Rom. J. Oral Rehab., 9(3), 89-96.

9. Shevchuk, M. N. (2018). Modern concepts of etiology and pathogenesis of inflammatory periodontal diseases. The Pharma Innovation Journal, 7(6), 170-173.

10. Lkhasaranova, I. B., \& Pinelis, Y. I. (2018). Spetsificheskiye i nespetsificheskiye faktory zashchity polosti rta $\mathrm{v}$ norme $\mathrm{i}$ pri khronicheskom generalizovannom parodontite. Zabaykalskiy meditsinskiy vestnik, № 1, 152163.

11. Zhuravleva, I. V., Ivanova, L. Y., \& Ivakhnenko, G. A. (2013). Studenty: povedencheskiye riski i tsennostnyye oriyentatsii v otnoshenii zdorovya. Vestnik Instituta sotsiologii, № 6, 112-129.

12. Guarnizo-Herreno, C., Watt, R., Pikhart, H., Sheiham, A., \& Tsakos, G. (2013). Socioeconomic inequalities in oral health in different European welfare state regimes. $J$ Epidemiol Community Health, 67(9), 728-735.

13. Kyungdo, H., \& Jun-Beom, P. (2017) Association between oral health behavior and periodontal disease among Korean adults. Medicine (Baltimore), Feb; 96(7), 61-76.

14. Sintsova, S. V., \& Chicherena, Y. N. (2011). Tabakokureniye - epidemiya XXI veka. Tuberkulez i bolezni legkikh, № 3, 23-26.

15. Bilano, V., et al. (2015). Global trends and projections for tobacco use, 1990-2025: an analysis of smoking indicators from the WHO
Comprehensive Information System for Tobacco Control. Lancet, 385(9972), 966-976.

16. (2018). WHO global report on trends in prevalence of tobacco smoking 2000-2025, second edition. (p.122). Geneva: World Health Organization.

17. Loshakova, L. Y., Pylkov, A. I., \& Semen'kova, O. V. (2010). Vliyaniye kureniya roditeley na intensivnost' porazheniya kariyesom vremennykh zubov ikh detey. Rossiyskiy stomatologicheskiy zhurnal, № 1, 25-28.

18. Fantuzzi, G., et al. (2008). Exposure to active and passive smoking during pregnancy and severe small-for-gestational-age at term. Journal of Maternal, Fetal and Neonatal Medicine, 21, 643-647.

19. Barrington-Trimis, J. L., et al. (2016). Ecigarettes, cigarettes, and the prevalence of adolescent tobacco use. Pediatrics, 138(2), e2028.

20. Bergstrom, J. (2014). Smoking rate and periodontal disease prevalence: 40 -year trends in Sweden, 1970-2010. J Clin Periodontol, 41, 952-957.

21. Nadezhdin, A. V., Tetenova, Y. Y., \& Sharova, Y. V. (2016). Zavisimost' ot nikotina: diagnostika i lecheniye. Zhurnal «Meditsina» № 3, 164-189.

22. Fagerstrom, K. O., \& Schneider, N. (1989). Measuring nicotine dependence: a review of the Fagerstrom Tolerance Questionnaire. J. Behav. Med., №12, 159-182. 